
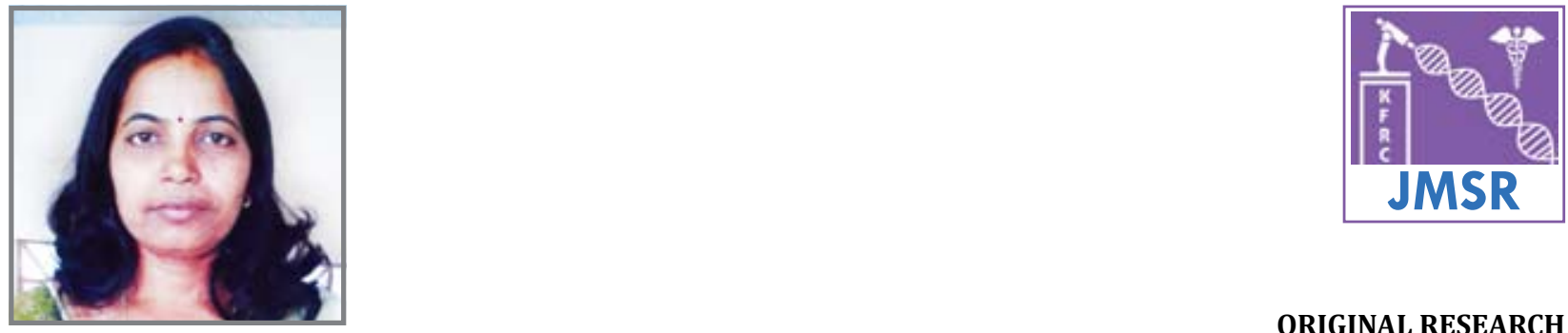

Dr. E. Syamala

ORIGINAL RESEARCH

\title{
Visceral fat correlation with sympathetic neuronal activity in women
}

Dr. E. Syamala1,2,", T. Rama Kranthi'², Nageshwari ${ }^{3}$, K. Amrutha Kumara², Sikandar Hussain ${ }^{2}$ and Pushpanjali $^{2}$

${ }^{1}$ Department of Physiology, Krishna Institute of Medical Sciences, Minister Road, Secunderabad - 500003, Telangana, India

${ }^{2}$ Dr. V.R.K. Womens Medical College and Research center, Hyderabad, Telangana, India

${ }^{3}$ Kamineni Institute of Medical Sciences, Hyderabad, Telangana, India

\section{Abstract}

Aim: The present study is undertaken to find out if obesity especially, visceral fat has any correlation with cardiovascular sympathetic activity in female undergraduate medical students.

Materials and methods: 24 females with mean age of $20 \pm 2$ of same community participated in the study. They were divided into 2 groups: Group I- Normal (BMI < 25), Group II -Obese (BMI > 30). Group II was again divided in to two subgroups, with normal visceral fat (VF), with increased visceral fat $(>10)$. Visceral fat, BMI and resting metabolism were measured using OMRON HBF - 362. Base line systolic blood pressure (SBP) and diastolic blood pressure (DBP) were measured. Sympathetic nerve activity was assessed using hand grip dynamometer, $30 \%$ of $\mathrm{T}_{\max }$ was calculated and simultaneously BP changes were monitored.

Results: Results were assessed using ' $\mathrm{t}$ ' test. A statistically significant difference $(<0.05)$ was observed in resting metabolism, baseline SBP, DBP and sympathetic activity between normal and obese groups. Baseline SBP varied significantly with visceral fat within the obese group.

Conclusion: The present study shows obesity increases sympathetic activity and visceral fat plays an important role in regulation of baseline BP, especially SBP even in young girls.

Keywords: Visceral fat; Obesity; Resting metabolism; Sympathetic activity

*Corresponding author: Dr. E. Syamala, Department of Physiology, Krishna Institute of Medical Sciences, Minister Road, Secunderabad - 500003, Telangana, India. Email: bhupathi.s@ rediffmail.com

Received 17 April 2014; Revised 22 May 2014; Accepted 3 June 2014

Citation: Syamala E, Rama Kranthi T, Nageshwari, Amrutha kumara K, Sikandar Hussain, Pushpanjali (2014) Visceral fat correlation with sympathetic neuronal activity in women. J Med Sci Res 2(3):149-152. DOI: http://dx.doi.org/10.17727/ JMSR.2014/2-027

Copyright: (C) 2014 KIMS Foundation and Research Centre. All Rights Reserved.

\section{Introduction}

According to World Health Organization (WHO) Worldwide, at least 2.8 million people die each year as a result of being overweight or obese. Lifestyle transition and socio-economic improvement have contributed enormously to the escalating problem of overweight and obesity among children in developing countries [1]. India ranks 15th position in female obesity and Andhra Pradesh ranks 10th position in India, with morbid obesity affecting $5 \%$ of the country's population [2]. Indians are 
genetically susceptible to weight accumulation especially around the waist, near to MC4R gene, scientists have identified a SNP (single nucleotide polymorphism) named as 12970134 to be mostly associated with waist circumference [3]. Obesity in Indian girls and women were found to have consistently higher obesity rates than Indian boys or men. Abdominal obesity, sometimes referred to as 'male-pattern' obesity is in fact more common in Indian women than in men [4]. Obesity is associated with increased muscle nerve sympathetic activity [5-11]. Sympathetic neural activation is an important feature of the metabolic syndrome $[6,7]$.

We estimated the regional fat distribution using body fat analyzer in obese and normal subjects. We assessed the sympathetic cardiovascular response to isometric exercise using handgrip dynamometer and found the correlation between visceral fat and sympathetic activity. The importance has been given to health education.

\section{Materials and methods}

The Institutional ethical committee clearance was obtained on 1-2-2012 from Dr.VRKWomen's Medical College and Research Centre, Hyderabad. 24 healthy females with mean age of $20 \pm 2$ of same community participated in this study. Females with overweight (BMI between 25 and 30) and any systemic disease were excluded from study. Written and informed consent was obtained from them. Subjects were divided into 2 groups: Group I- Normal $(\mathrm{BMI}<25)$ $(n=12)$ and Group II -Obese (BMI $>30)(n=12)$. Group II was again divided in to two subgroups i.e. (i) with normal visceral fat (VF) $(n=6)[1-9]$ and (ii) with increased visceral fat $(>10)(n=6)$. Subjects were asked to relax in supine posture for 15 minutes and base line systolic blood pressure (SBP) and diastolic blood pressure (DBP) were measured using sphygmomanometer.

Visceral fat, BMI, resting metabolism were measured using OMRON body composition monitor with scale (HBF-362)-karada [12] scan, which estimate the body fat percentage by the bioelectrical impedance (BI) method. Muscles or blood vessels are body tissues with a high water content that conducts electricity easily. Body fat tissue has low electric conductivity. The HBF-362 sends an extremely low electrical current of $50 \mathrm{kHz}$ and less than $500 \mu \mathrm{A}$ through our body to determine the amount of fat tissue. This weak electrical current is not felt while operating the HBF-362. In order for the scale to determine body composition, it uses the electrical impedance, along with height, weight, age and gender information to generate results based on OMRON's data of body composition. Sympathetic nerve activity was assessed using Hand grip test (Isometric exercise) and resting BP was recorded. The subject was asked to compress the Hand grip dynamometer $\left(30 \%\right.$ of $\mathrm{T}_{\max }$ ) for 3 minutes and $\mathrm{BP}$ was recorded simultaneously from non-exercising arm, values were recorded immediately after 1 minute and after 3 minutes. BP changes during 3 minutes were considered for statistical analysis. Statistical analysis of results were assessed using un paired ' $t$ ' test using MINITAB 14 software.

\section{Results}

A statistically significant difference $(<0.05)$ was observed between normal and obese groups i.e. baseline SBP [0.01], DBP [0.007], resting metabolism [0.00], and $\mathrm{T}_{\max }$ SBP [0.03]. The $\mathrm{T}_{\max }$ DBP was insignificant [0.06] (Table 1).

Table 1: Comparison of parameters between normal and obese groups.

\begin{tabular}{|llll|}
\hline & Group I & Group II & P value \\
\hline SBP & $105.8 \pm 9.0$ & $115.33 \pm 7.8$ & 0.010 \\
DBP & $69.16 \pm 7.92$ & $76.5 \pm 5.1$ & 0.007 \\
RM & $1131.5 \pm 99.31$ & $1505.2 \pm 152.24$ & 0.000 \\
$\mathrm{~T}_{\max }$ SBP & $116.6 \pm 9.81$ & $131.6 \pm 18.9$ & 0.035 \\
$\mathrm{~T}_{\max }$ DBP & $84.50 \pm 10.20$ & $92.66 \pm 8.32$ & 0.060 \\
\hline
\end{tabular}

Abbreviations: $\mathrm{SBP}=$ Systolic blood pressure; $\mathrm{DBP}=$ Diastolic blood pressure; $\mathrm{RM}=$ Resting metabolism; $\mathrm{T}_{\max } \mathrm{SBP}, \mathrm{T}_{\max } \mathrm{DBP}$ = systolic blood pressure $\&$ diastolic blood pressures during isometric exercise.

Baseline SBP [0.028] varied significantly with visceral fat within the obese group (increased linearly with increase in visceral fat) and the remaining base line DBP [0.93], RM [0.18], $\mathrm{T}_{\max }$ SBP [0.37] and $\mathrm{T}_{\max }$ DBP [0.30] did not show significant variation (Table 2). 
Table 2: Comparison of parameters in obese individuals with normal viceral fat and increased visceral fat.

\begin{tabular}{|llll|}
\hline & Normal VF & Increased VF & P value \\
\hline SBP & $111.66 \pm 7.52$ & $119.0 \pm 6.78$ & 0.028 \\
DBP & $76.66 \pm 5.16$ & $76.33 \pm 5.71$ & 0.93 \\
RM & $1428.17 \pm 88.63$ & $1582.33 \pm 169.9$ & 0.184 \\
$\mathrm{~T}_{\max }$ SBP & $126.66 \pm 12.11$ & $136.66 \pm 24.22$ & 0.377 \\
$\mathrm{~T}_{\max }$ DBP & $95.00 \pm 10.02$ & $90.33 \pm 6.25$ & 0.302 \\
\hline
\end{tabular}

Abbreviations: SBP = Systolic blood pressure; DBP = Diastolic blood pressure; $\mathrm{RM}=$ Resting metabolism; $\mathrm{T}_{\max } \mathrm{SBP}, \mathrm{T}_{\max } \mathrm{DBP}$ = systolic blood pressure $\&$ Diastolic blood pressure during isometric exercise.

\section{Discussion}

The present study shows increase in resting metabolism which supports the study done by Eric Ravussin et al. [13] and might be due to greater

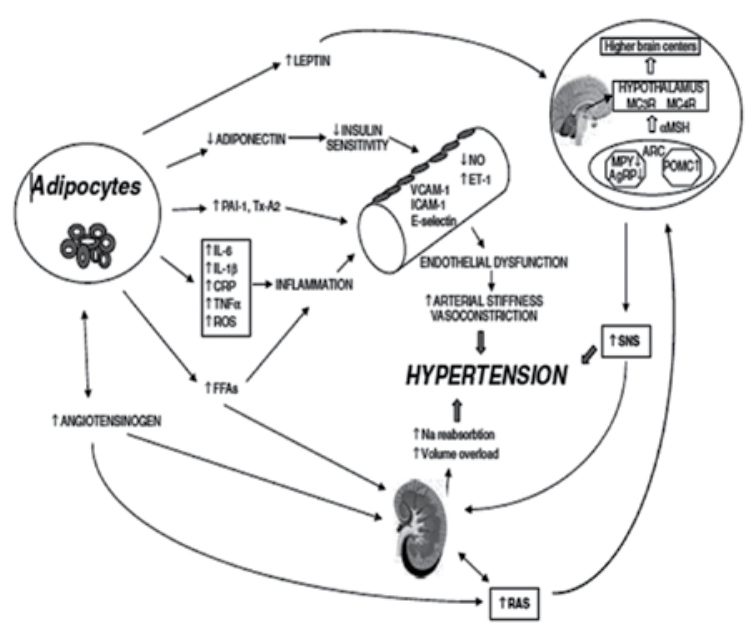

Figure 1: Mechanisms involved in the pathogenesis of obesityinduced hypertension [17].

Abbreviations: PAI-1 = plasminogen activator inhibitor-1; Tx-A2 = thromboxane A2; IL-6 = interleukin-6; IL-1b = interleukin-1b; $\mathrm{TNFa}=$ tumor necrosis factor-a; CRP = C-reactive protein; ROS $=$ reactive oxygen species; FFAs = free-fatty acids; VCAM-1 = vascular cell adhesion molecule-1; ICAM-1 = inter-cellular adhesion molecule-1; NO= nitric oxide; ET-1 = endothelin-1; RAS = rennin-angiotensin system; SNS = sympathetic nervous system; AgRP = agouti-related peptide; $\mathrm{NPY}=$ neuropeptide $\mathrm{Y} ; \mathrm{POMC}=$ proopiomelanocortin; $\mathrm{ARC}=$ arcuate nucleus; $\mathrm{a}-\mathrm{MSH}$ = a-melanocytestimulatinghormone; MC3R = melanocortin 3 receptor; MC4R = melanocortin 4 receptor.
V02. The present study also supports increased sympathetic activity in obese individuals especially with greater visceral fat [15-18] in contrast to other studies, which showed decreased sympathetic activity in obese $[19,20]$. Few studies reported that both divisions of ANS are impaired in obese [21]. Fat distribution is two types i.e. (i) subcutaneous fat, characterized by insulin-sensitive adipocytes, (ii) visceral fat adipocytes are insulin-resistant cells. Visceral fat may cause Hypothalamo-pituitaryadrenal axis dysregulation and may contribute to elevated basal sympathetic activity [18]. Plasma renin activity, angiotensinogen, angiotensin II and aldosterone values display significant increase during obesity and may cause volume overload [22] which may also contribute to increase in blood pressure and sympathetic activity.

\section{Conclusion}

The present study shows obesity increases resting metabolism. Sympathetic activity and visceral fat plays an important role in regulation of baseline $\mathrm{BP}$, especially SBP even in young girls and may predispose to the development of hypertension. Main limitation of this study is limited sample size and future studies are required large sample size.

\section{Conflict of interest}

The authors declare no conflict of interest.

\section{References}

1. Maiti S, Chatterjee K. Overweight and Obesity among Urban Bengalee Early Adolescent School Girls of Kharagpur, West Bengal, India. Iran J Pediatr. 2013; 23(2):237-238.

2. India facing obesity epidemic, experts: The Hindu. 12-102007.

3. Nurmi EL, Spilman SL, Whelan F, Scahill LL, Aman MG, et al. Moderation of antipsychotic-induced weight gain by energy balance gene variants in the RUPP autism network risperidone studies. Transl Psychiatry. 2013; 3:e274. doi: 10.1038/tp.2013.26.

4. Chopra SM, Misra A, Gulati S, Gupta R. Overweight, obesity and related non-communicable diseases in Asian Indian girls and women. Eur J Clin Nutr. 2013; 67(7):688-696. doi: 10.1038/ejcn.2013.70.

5. Grassi G, Seravalle G, Cattaneo BM, Bolla GB, Lanfranchi A, et al. Sympathetic activation in obese normotensive subjects. Hypertension 1995; 25:560-563.

6. Reaven GM, Lithell H, Landsberg L. Hypertension and associated metabolic abnormalities: the role of insulin resistance and the sympatho-adrenal system. N Engl J Med. 1996; 334:374-381.

7. Brook RD, Julius S. Autonomic imbalance, hypertension, and cardiovascular risk. Am J Hypertens. 2000; 13:112S-122S. 
8. Grassi G, Seravalle G, Colombo M, Bolla G, Cattaneo BM, et al. Body weight reduction, sympathetic nerve traffic, and arterial baroreflex in obese normotensive humans. Circulation. 1998; 97:2037-2042.

9 Grassi G, Seravalle G, Dell'Oro R, Turri C, Pasqualinotto L, et al. Participation of the hypothalamus-hypophysis axis in the sympathetic activation of humanobesity. Hypertension. 2001; 38:1316-320.

10. Scherrer U, Randin D, Tappy L, Vollenweider P, Jéquier E, et al. Body fat and sympathetic nerveactivity in healthy subjects. Circulation. 1994; 89:2634-2640.

11. Spraul M1, Ravussin E, Fontvieille AM, Rising R, Larson DE, et al. Reduced sympathetic nervous activity: a potential mechanism predisposing to body weight gain. J Clin Invest. 1993; 92:1730-1735.

12. Rohin MAK, Rozano N, Hadi NA, Nor MNM, Abdullah S, et al. Anthropometry and Body Composition Status during Ramadan among Higher Institution Learning Centre Staffs with Different Body Weight Status. The Scientific World Journal 2013; 2013:308041.

13. Ravussin E, Burnand B, Schutz Y, Jéquier E. Twenty four hour energy expenditure and resting metabolic rate in obese, moderately obese and control subjects. Am J Clin Nutr. 1982; 35(3):566-573.
14. Hall JE, Brands MW, Hildebrandt DA, Kuo J, Fitzgerald S. Role of sympathetic nervous system and neuropeptides in obesity hypertension. Braz J Med Biol Res. 2000; 33(6):605-618.

15. Canale MP, Manca di Villahermosa S, Martino G, Rovella $\mathrm{V}$, Noce A, et al. Obesity-related metabolic syndrome: mechanisms of sympathetic over activity. Int J Endocrinol. 2013; 2013:865965. doi: 10.1155/2013/865965.

16. Davy KP, Orr JS. Sympathetic Nervous System Behavior in Human Obesity. Neurosci Biobehav Rev. 2009; 33(2): 116124.

17. Kotsis V, Stabouli S. Mechanisms of obesity-induced hypertension. Hypertension Research 2010; 33:386-393;

18. Alvarez GE, Beske SD. Sympathetic Neural Activation in Visceral Obesity. Circulation 2002; 106:2533-2536.

19. Esler M, Lambert G. Sympathetic nerve activity and neurotranmitter release in humans: translation from pathophysiology into clinical practice. Act Physiol Scand. 2003; 177:275-284.

20. Bedi M, Khullar S. Assessmnt of autonomic activity in obese children. Vascular Disease Prevention 2009; 6:139-141.

21. Grewal S, Gupta V. Effect of obesity on autonomic nervous system. Int J Cur Bio Med Sci. 2011; 1(2):15-18.

22. Kotsis V, Stabouli S. Mechanisms of obesity-induced hypertension; Hypertension Research 2010; 33:386-393. 